\title{
Correction to: Comparison of Self-Organizing Map, Artificial Neural Network, and Co-Active Neuro-Fuzzy Inference System Methods in Simulating Groundwater Quality: Geospatial Artificial Intelligence
}

\author{
V. Gholami ${ }^{1} \cdot$ M. R. Khaleghi² ${ }^{2} \cdot$ S. Pirasteh ${ }^{3} \cdot$ Martijn J. Booij $^{4}$ \\ Published online: 6 January 2022 \\ (c) Springer Nature B.V. 2021
}

\section{Correction to: Water Resour Manag https://doi.org/10.1007/s11269-021-02969-2}

In this article, the city of the third affiliation was mistakenly given. The original article has been corrected.

Publisher's Note Springer Nature remains neutral with regard to jurisdictional claims in published maps and institutional affiliations.

The original article can be found online at https://doi.org/10.1007/s11269-021-02969-2.

M. R. Khaleghi

drmrkhaleghi@gmail.com

1 Department of Range and Watershed Management and Dept. of Water Eng. and Environment, Faculty of Natural Resources, University of Guilan, 1144 Sowmeh Sara, Guilan, Iran

2 Torbat-E-Jam Branch, Islamic Azad University, Torbat-e-Jam, Iran

3 Department of Geoinformatics and Surveying, Faculty of Environmental and Engineering, Southwest Jiaotong University, Chengdu, China

4 Water Engineering and Management, Faculty of Engineering Technology, University of Twente, Enschede, the Netherlands 